\title{
The object of psychoanalysis: Jacques Lacan's object a
}

\author{
Thomas Brockelman • Dominiek Hoens
}

(C) Springer Science+Business Media Dordrecht 2013

One of the editors of this number of Continental Philosophy Review was once invited to give a talk on contemporary continental philosophy at a major university in the United States. When asked what issue or thinker he should address, the university's representative only specified, "anything but Lacan." A first way to understand the following collection of philosophical interpretations of Jacques Lacan's work is as a response to that functionary's attitude and, let's face it, the attitude of many even within the "minority culture" of continental philosophy, that Lacanian psychoanalysis is somehow, "not quite the thing"-either too obscure, or not radical enough or, even, not sufficiently rigorous. Perhaps the most obvious way in which this collection marks a response, is in the nature and quality of the papers contained within it. Almost all are essays from a generation of thinkers after Lacan himself, a generation that, largely by the ethical force, revolutionary vision and discipline of its philosophical scholarship, has prevented Lacanian analysis from slipping into the historical abyss of fads. The quality of work being done today following Lacan speaks for itself. The case for allowing it to be included in whatever we might call "mainstream" continental philosophy follows simply from reading the representative samples collected in this volume.

On the other hand, the common theme of the essays collected here is by no means accidental to the success of the Lacanian tradition, if, nonetheless, it remains an under-emphasized cause: this is what Lacan distinguishes as the specific "objectcause" of psychoanalysis, an object that, just to cite one coordinate among many possible ones, differentiates the work of analysis from that of other sciences. Lacan even hints that the conception of the object a may be the "cornerstone" of his work

\footnotetext{
T. Brockelman $(\bowtie)$

Le Moyne College, 1419 Salt Springs Road, Syracuse, NY 13214, USA

e-mail: brocketp@lemoyne.edu

D. Hoens

Erasmus University College Brussels, Dansaertstraat 70, 1000 Brussels, Belgium

e-mail: dominiek.hoens@ehb.be
} 
(Seminar XIII) and considers it as his sole "invention" (Seminar XXI). And yet, certain difficulties have prevented full exposition of that key idea: first, we must mention the difficulty of Lacan's discussions of the object $a$, a concept that develops over the course of his career but that marks something like the boundary of his thought at every point. Moreover, there is a contingency of publishing history that contributes to the shroud of mystery over the psychoanalytic object: the year of Lacan's seminar explicitly dedicated to "The Object of Psychoanalysis" (1965-66), remains unpublished. While the first session of that year appeared in edited form as "Science and Truth" first in the seminal issue of Cahiers pour l'analyse (1966) and then in the full text of the Ecrits (1966), the rest of the seminar remains unedited and, while available in various unofficial transcripts, unpublished.

It is our contention that the time has come to surmount the roadblocks in the way of understanding the "object of psychoanalysis" and, thus perhaps, Lacan himself. Here, again, we depend for support on the manifest evidence of the essays collected in this volume of Continental Philosophy Review - of their success at making sense of this "cornerstone" of Lacan's work. First of all, in the papers of Dany Nobus, Marc de Kesel and Richard Boothby (in the section of the volume entitled "The Emergence of object $a$ in Lacan"), we have gathered three genetic accounts of how Lacan's mature concept emerges. While these authors differ in their emphases and thus in the lessons that they draw from this history, together these accounts give the interested layman an excellent place to start in understanding object $a$. If the first section attempts to tell us just what Lacan means by object $a$, the second part (essays by Mladen Dolar, Dominiek Hoens and Adrian Johnston) addresses the question of why we should care about it-locating Lacan's concept in the history of thought. The third section of this number addresses an underappreciated dimension of Lacanian thought. In including essays by Thomas Brockelman, Sigi Jöttkandt and Todd McGowan all dedicated to "the aesthetics of object a," we have suggested some of the ways in which a "psychoanalytic" approach to literary or artistic works can be aesthetically fruitful. In doing this we have both tried to combat the harmful prejudices according to which psychoanalysis, with its reductive, "scientific" emphasis, must be opposed to a purely aesthetic viewpoint and attempted to explain just why there in fact is so much fruitful aesthetic understanding in Lacan-inspired interpretations of art.

This emphasis upon Lacan's contribution to aesthetics continues in the final chapter in our collection-an English translation of a piece by Lacan himself, produced, along with a scholarly set of explanatory annotations, by Dany Nobus. The essay, Lituraterre completed in 1971 marks one of Lacan's most extensive efforts to think-through the aesthetic implications of object $a$. It is also a fascinating literary text on its own, a meditation on the "literary" and a valentine to James Joyce's Finnegans Wake. Nobus' annotated translation of Lacan's essay, long in preparation, itself marks a major publishing milestone and an important step in the project of making Lacan's entire oeuvre available to the English-speaking world.

If we have explained this number of Continental Philosophy Review with regard to its purpose and its form, we'd be remiss if we did not also mention its occasion, the event that at least suggested the final product as a possibility. That occasion was a series of events organised by the Circle for Lacanian Ideology Critique (CLiC). 
CLiC was hosted from 2004 until 2012 by the Jan van Eyck Academie in Maastricht, The Netherlands, and, as part of its ongoing activities, Dominiek Hoens organised both a 2007-2008 reading group dedicated to Lacan's Seminar XIII, The Object of Psychoanalysis (1965-1966, unpublished) and a one day colloquium ("Object Day") in June 2009 at which some of the authors presented initial reflections. CLiC at the JVE provided both the specific context for this volume and the general circumstances in which creative scholarly work of this kind can thrivethe resources to gather those engaged in interesting research and the venue for productive dialogue. With its very future currently in doubt due to budgetary pressures, it is to the Jan van Eyck Academie and its former director, Koen Brams, that we dedicate this volume. 